ORIGINAL ARTICLE

\title{
Study of psychiatric morbidity of patients attending free mental health check up camp, Simara, Bara district of Nepal
}

\author{
Sedain C $P^{*}$ \\ Department of Psychiatry, Chitwan Medical College Bharatpur,Chitwan, Nepal \\ Email *Corresponding author: drcpsedai@yahoo.com
}

\begin{abstract}
Introduction: Maryknoll Nepal has been running community mental health clinics different part of the country. The aim of the study was to find out psychiatric morbidity of patients attending Maryknoll free check up clinic Simara, Bara district of Nepal.
\end{abstract}

Methods: A prospective cross-sectional study comprised of all consecutive patients attending Maryknoll free check up clinic Simara, Bara district, Nepal. All the patients attending the free clinics were taken as cases. The study was conducted in January 2009. Demographic data and disease profile of 87 patients attending the clinic were analyzed. The ratios and proportions were used for statistical analysis.

Results: Data from Simara free mental health clinic shows that the male to female ratio was 0.55:0.44. The age group 30-39(N-25, 28.74\%) followed by age group $20-29(\mathrm{~N}-19,21.84 \%)$ was the commonest. The farmer were $(\mathrm{N}-49,56.31 \%)$ the most common visitor. The highest number of cases were depressive disorder (N-16, $18.93 \%)$ followed by mania/BPAD (N-14, $16.09 \%)$ and Schizophrenia (N-12, $13.73 \%$ ).

Conclusion: The commonest incidence of psychiatric illness attending the free clinic is depressive disorder and mania/BPAD.

Key words: diagnosis profile, socio-demographic characteristics, BPAD

\section{INTRODUCTION}

$\mathrm{M}$ aryknoll Nepal, a local NGO, has been working in the area of mental health since 1991, concerning mobile community mental health clinics in different region of the country. Besides community mobile clinics it is working psychosocial rehabilitation, public awareness programme, day care progamme and home visit programme.The mobile health clinics tries to cover urban as well as remote area of Nepal. These types of program helps people in the remote area, where mental health facility is not available are expected to benefit. This study was done in free mental health check up camp Simara, Bara district of Nepal, where regular monthly free check up of mentally ill people has been started for last five year.

Studies regarding psychiatric morbidity are scare in Nepal. Thus the studies in this aspect becomes important, mainly to formulate any plan regarding mental illness 1. There are few studies on mental illness. About half of the patients in all studies were of the age group 20-40 years and more than half were males. However the diagnostic distribution differed among the studies. Thus despite the inconsistencies in the diagnostic distribution, the findings in the 
different setup have their own importance². The Quality Adjusted Life Year (QALY) losses in primary care is highest is in pain related physical condition followed by mood disorder ${ }^{3}$.

Major depression is the most common psychiatric problem seen in primary care. Prevalence figures for major depression vary substantially between surveys ${ }^{4}$. The reasons for increased rates among women are uncertain. Depression is more common among the unemployed; divorced, all medical illness and their treatment can act as non-specific stress, which may lead to mood disorder in predisposed subject. The present study was conducted to find out psychiatric morbidity of patients attending Maryknoll free check up clinic Simara, Bara district of Nepal.

\section{METHOD}

A prospective cross-sectional study comprised of all consecutive patients attending Maryknoll free check up clinic Simara, Bara district, Nepal. All the patients attending the free clinics were taken as case. The study was performed in January 2009.A brief explanation about the study was offered to the subjects and written or verbal consent was obtained either from them or guardians. A continuous sequential number was given to each subject and available necessary information was kept confidential in a separate file. The socio demographic profile which contains name, age, sex, caste, address, marital status, occupation, and other information also filled. The diagnosis was done on the basis of International Classification of Disease - 10 diagnostic research criteria ${ }^{5}$.Data from previous months was also taken for make study easier. To take more information previous record of the camp was also studied. Data were entered in to a computer and analyzed using Statistical Package for Social Studies (SPSS) software.

\section{RESULT}

A total of 87 patients were included in the study. Out of them male were $48(55.17 \%)$ and female were 39 (44.83\%). Data shows highest numbers of patients were age group $30-39(\mathrm{~N}-25,28.74 \%)$ followed by age group 20-29 (N-19, 21.84\%). Data shows highest numbers of patient were married $(\mathrm{N}-59$, $67.82 \%)$ and most of cases were farmer $(\mathrm{N}$ $49,56.31 \%$ ).Distribution on the basis of ICD 10 diagnosis, highest number of cases were depressive disorder (N-16,18.93\%) followed by mania/BPAD (N-14, $16.09 \%$ ) and Schizophrenia(N-12, $13.73 \%)$.Similarly seizure disorder (N-9, $10.34 \%)$, and ,somatoform disorder (N-7, $8.05 \%)$., alcohol use disorder (N-6, $6.09 \%$ ).anxiety disorder (N-6, $6.09 \%$ ), conversion disorder $(\mathrm{N}-5,5.75 \%)$ and tension/migraine headache $(\mathrm{N}-4,4.60 \%)$.

Table 1: Age wise characteristics of the respondents

\begin{tabular}{ccc}
\hline AGE & N & $\%$ \\
\hline $10-19$ & 12 & 13.73 \\
\hline $20-29$ & 19 & 21.84 \\
\hline $30-39$ & 25 & 28.74 \\
\hline $40-49$ & 18 & 20.69 \\
\hline $50-59$ & 7 & 8.05 \\
\hline $60-69$ & 4 & 4.58 \\
\hline $70-79$ & 2 & 2.30 \\
\hline TOTAL & 87 & 100
\end{tabular}

Table 2: Distribution on the basis of sex

\begin{tabular}{lcc}
\hline SEX & CASE & $\%$ \\
\hline MALE & 48 & 55.17 \\
\hline FEMALE & 39 & 44.83 \\
\hline TOTAL & 87 & 100
\end{tabular}


Table 3: Marital status of the respondents

\begin{tabular}{lcc} 
MARITAL STATUS & $\mathbf{N}$ & $\mathbf{0}$ \\
\hline Married & 59 & 67.82 \\
\hline Unmarried & 23 & 26.44 \\
\hline Widowed & 5 & 5.75 \\
\hline Total & $\mathbf{8 7}$ & $\mathbf{1 0 0}$
\end{tabular}

Table 4: Distribution on the basis of occupation

\begin{tabular}{lcc} 
Occupation & $\mathbf{N}$ & $\mathbf{\%}$ \\
\hline Farmer & 49 & 56.31 \\
\hline Businessman & 3 & 3.45 \\
\hline Service holder & 8 & 9.20 \\
\hline Housewife & 9 & 10.34 \\
\hline Labour & 7 & 8.05 \\
\hline Unemployed & 7 & 8.05 \\
\hline Student & 4 & 4.60 \\
\hline Total & $\mathbf{8 7}$ & $\mathbf{1 0 0}$
\end{tabular}

Table-5: Distribution on the basis of diagnosis (ICD-10 DCR)

\begin{tabular}{lllll}
$\begin{array}{l}\text { Diagnosis- } \\
\text { icd,10 }\end{array}$ & Male & Female & Total & \% \\
\hline $\begin{array}{l}\text { Depressive } \\
\text { disorder(f32) }\end{array}$ & 7 & 9 & 16 & 18.3 \\
\hline $\begin{array}{l}\text { Schizophreni } \\
\text { a (f20) }\end{array}$ & 6 & 6 & 12 & 13.7 \\
\hline $\begin{array}{l}\text { Seizure } \\
\text { disorder } \\
\text { (g40) }\end{array}$ & 4 & 5 & 9 & 10.3 \\
\hline $\begin{array}{l}\text { Mania/bpad } \\
\text { (f30-31) }\end{array}$ & 8 & 6 & 14 & 16.0 \\
\hline $\begin{array}{l}\text { Anxiety } \\
\text { disorder } \\
\text { (f4o-41) }\end{array}$ & 4 & 2 & 6 & 6.9 \\
\hline $\begin{array}{l}\text { Alcohol use } \\
\text { disorder (f10) }\end{array}$ & 5 & 1 & 6 & 6.9 \\
\hline $\begin{array}{l}\text { Substance } \\
\text { use disorder } \\
\text { (f11-19) }\end{array}$ & 3 & 0 & 3 & 3.4 \\
\hline $\begin{array}{l}\text { Conversion } \\
\text { donder (f4) }\end{array}$ & 0 & 5 & 5 & 5.7
\end{tabular}

disorder (f44)

\begin{tabular}{lllll}
$\begin{array}{l}\text { Dementia } \\
\text { (f00-03) }\end{array}$ & 1 & 0 & 1 & 1.1 \\
\hline Ptsd (f43) & 1 & 0 & 1 & 1.1 \\
\hline $\begin{array}{l}\text { Somatoform } \\
\text { disorder (f45) }\end{array}$ & 4 & 3 & 7 & 8.0 \\
\hline $\begin{array}{l}\text { Sleep } \\
\text { disorder (f51) }\end{array}$ & 1 & 0 & 1 & 1.1 \\
\hline $\begin{array}{l}\text { Mental } \\
\text { retardation } \\
\text { (f70-79) }\end{array}$ & 1 & 0 & 1 & 1.1 \\
\hline Ocd(f42) & 1 & 0 & 1 & 1.1 \\
\hline $\begin{array}{l}\text { Tension/mig } \\
\text { rain } \\
\text { headache } \\
\text { (g43-44) }\end{array}$ & 2 & 2 & 4 & 4.6 \\
\hline Total & $\mathbf{4 8}$ & $\mathbf{3 9}$ & $\mathbf{8 7}$ & $\mathbf{1 0 0}$
\end{tabular}

\section{DISCUSSION}

The life style is becoming complex day by day, thus the patients consulting the psychiatrist is increasing than previous decade. Depressive disorder is the commonest psychiatric disorders worldwide. A review of anxiety disorder surveys in different countries found that average lifetime prevalence estimates of $16.6 \%$, with women having higher rates on average ${ }^{6}$.A review of mood disorder surveys in different countries found that lifetime rates of $6.7 \%$ for major depressive disorder (higher in some studies, and in women) and $0.8 \%$ for Bipolar I disorder- In the United States the frequency of disorder is: anxiety disorder (28.8\%), mood disorder (20.8\%), impulse-control disorder $(24.8 \%)$ or substance use disorder $(14.6 \%)^{7}$.A 2004 cross-Europe study found that approximately one in four people reported meeting criteria at some point in their life for at least one of the DSM-IV psychiatric disorders assessed, which included mood disorders $(13.9 \%)$, anxiety disorders $(13.6 \%)$ or alcohol disorder (5.2\%). Approximately one in ten met criteria within a 12-month period. Women and younger people of either gender showed more cases of disorder. A 2005 review of surveys in 16 European countries found that $27 \%$ of adult 
Europeans are affected by at least one mental disorder in a 12 month period 8 .

Psychiatric disorder like schizophrenia, BPAD, alcohol \& drug addiction problems are also equally challenging to us. A tenyear perspective study in Zurich, estimated the life time prevalence of major depression is about 16 percent. The rate of depressive disorder seems to be higher in industrialized countries ${ }^{9}$. They are consistently increased in woman across different cultures. Regmi et al reported that patients attending to psychiatric OPD of TUTH were commonly neurotic and harboring stress related disorder ${ }^{2}$. Pokhrel et al reported that mood disorder (35\%) followed by schizophrenia and related disorder (28\%) and neurotic and stress related disorder $(17 \%)$ respectively ${ }^{3}$. The percentage distribution of depressive illness reported by Sharma is similar to our finding. Major depression is the commonest psychiatric problem seen in primary care center. Depression is more common among the unemployed and divorced people. If we look at our finding the depressive illness was observed among the patient of SLC and intermediate education level. All medical illnesses and their treatment can act as nonspecific stress factor which may lead to mood disorder in predisposed subject. Prevalence of psychiatric disorders among general hospital population is higher than in community.

Patients with psychiatric disorder do present with symptoms of medical illnesses. Psychiatric disorders can be the consequence or coexist with medical illness. Many previous studies have shown that psychiatric disorders such as depressive disorder, anxiety disorder, drug abuse, organic mental disorders and somatoform disorder could be encountered approximately in 20-80 percent of inpatients in any of the general hospitals worldwide. About $20 \%$ of our patient admitted in medical and gynecology departments, especially female patient, have some psychiatric problems in the form of mood disorder and somatoform disorder.

\section{CONCLUSION}

The Maryknoll free mental health check up clinic Simara, Bara shows depressive disorder is the commonest psychiatric disorder. Similarly other disorders include mania/BPAD, schizophrenia, seizure disorder, somatoform disorder, alcohol use disorder, anxiety disorder and conversion disorder.

\section{REFERENCES}

1. Pokhrel et al. Sociodemographic characteristics and diagnostic profile of patients admitted in psychiatric ward of TUTH, Katmandu. Nepalese Journal of psychiatry $1992 ;(2): 13-17$.

2. Regmi et al. Studies of sociodemographic characteristics and diagnostic profile in psychiatric outpatient of TUTH. Nepalese Journal of psychiatry 1999; 1: 26-33.

3. Fernandz A. ,Sammeno JB , PrintoMeza A ,Luciano V .et al. Burden of chronic condition and mental disorder in primary care, British jurnal of psychiatry,2010;196:302309.

4. Smith AL, Weissman MM, Smith. Cross national epidemiology of major depression and bipolar disorder. Journal of American medical association. 1992.

5. World Health Organization. International Classification of disease and related heath problems, Tenth revision: Clinical description and diagnostic guideline; Geneva: World Health Organization. 1992

6. Kessler RC, Berglund P, Demler O, Jin R, Merikangas KR, Walters EE. Lifetime prevalence and age-ofonset distributions of DSM-IV disorders in the National Co morbidity Survey Replication. Arch. Gen. Psychiatry 2005; 62 (6): 593-602.

7. Waraich P, Goldner EM, Somers JM, Hsu L. Prevalence and incidence studies of mood disorders: a 
systematic review of the literature. Can J Psychiatry 2004; 49: (2): 12438.

8. Alonso J, Angermeyer MC, Bernert $S$, et al. Prevalence of mental disorders in Europe: results from the European Study of the Epidemiology of Mental Disorders (ESEMeD) project. Acta Psychiatr Scand Suppl. 2004; 109: (420): 21-7.

9. Angst. J. How recurrent and predictable is depressive illness? In long term treatment of depression, eds S. Montgomery and F Rouillon.Wiley, Chichester; 1992:1-3. 